\title{
LUGARES DA PESQUISA E ENSINO NAS HUMANIDADES NO SÉCULO XXI ${ }^{1}$
}

MARIA TARCISA SILVA BEGA²

Se fosse minimamente coerente, a universidade fecharia, todo fim de ano, para balanço, sem qualquer restrição. Repensaria os cursos, a própria ideia de curso, os resultados de aprendizagem e os diplomas, modos de avaliar e de cuidar da aprendizagem dos alunos. Repensaria seus professores, títulos, carreiras, concursos. Colocaria em xeque as aulas, todas, para, percebendo esta engrenagem particularmente imbecilizante, retomar a aprendizagem condizente ao direito dos alunos de aprender bem. Repensaria a instituição, hoje reduzida a um monte de sala de aulas e currículos ultrapassados, como se ser profissional fosse tirocínio drástico de entupimento de conteúdos, todos já obsoletos.

Repensaria graduação, pós-graduação, mestrado, doutorado, porque são resquícios de mundos perdidos que já não valem mais. Repensaria a hierarquia docente, para privilegiar a habilidade de desconstrução e reconstrução de conhecimento, não os trambiques institucionais que giram em torno das vaidades e cargos. Repensaria a relação com os alunos, condenados a valorizar e a pagar por informação ultrapassada e que pode encontrar em outros cantos mais fácil e sistematicamente. Repensaria os campi, cuja estrutura física não vale o que custa, nem de longe. Levaria em conta os horizontes abertos de aprendizagem via presença virtual, as motivações dos alunos em contato com computador e internet, os modos mais interativos e caóticos de aprender das novas gerações.

Levaria em conta a diversidade de ritmos e recursos, abrindo espaço para estudo mais e menos longo, sem perda de qualidade. Centraria o compromisso na formação pela via da pesquisa e elaboração própria, tendo como objetivo sedimentar a formação permanente, o saber pensar, a produção interativa e coletiva de conhecimento, o uso intensivo das novas tecnologias. Profissionais do futuro precisam preparar-se para dar conta dos desafios dos quais hoje não possuem qualquer ideia. (DEMO, 2005:12)

A partir desse excerto demolidor sobre a estrutura universitária e sobre nosso cotidiano como agentes nesta estrutura, proponho iniciar nossa reflexão sobre os lugares do Ensino e da pesquisa na universidade, com destaque para as Humanidade, no século XXI. Em primeiro lugar agradeço à Comissão Executiva do XI Seminário de Pesquisa em Ciências Humanas na pessoa do Professor Doutor Fernando Kulaitis pelo convite, que me permitiu refletir sobre este tema tão presente nas nossas vidas de docente-pesquisador, bem como a respeito da minha experiência pessoal como gestora na Universidade Federal do Paraná.

Antes de discutir os desafios para este século que ainda se inicia, entendo como socióloga que trabalha com reconstrução histórica, ser necessário lembrar do surgimento da

\footnotetext{
${ }^{1}$ Conferência de Abertura do XI Seminário de Pesquisa em Ciências Humanas - SEPECH Humanidades, Estado e desafios didático-científicos, Universidade Estadual de Londrina, 27 de julho de 2016

${ }^{2}$ Socióloga, professora do Departamento de Sociologia e do Programa de Pós-Graduação em Sociologia da Universidade federal do Paraná. tarcisa.silva@gmail.com
} 
Universidade, os modelos dominantes que se estabelecem a partir do século XIX e, depois o caso brasileiro. Este, mais recente, materializado como projeto nacional na Segunda República a partir dos anos da década de 1930.Assim contextualizado o quadro da universidade, discutimos a posição das Humanidades e os desafios da Pesquisa e do Ensino nesta grande área, para o século XXI.

\section{HISTÓRICO DA UNIVERSIDADE}

A palavra Universidade deriva do latim universus, formada por unus, que significa um e versus, que é o particípio passado do verbo vertere, que significa voltar-se, tornar-se. Daí universidade ter o significado etimológico profundo de "tornar-se um", ou seja, expressar a diversidade na unidade.

Como instituição social nasce marcada pela presença da Igreja Católica Romana que a balizou com consideráveis restrições de pensamento e de pesquisa. Fundada em Bolonha em data incerta (1089 ou 1093), respondeu aos ditames de uma sociedade medieval, isto é, currículo simples e recursos limitados, com uma função docente de simples transmissora e repetidora de conhecimentos estabelecidos. Permanece nesse formato, sem mudanças substantivas, até o século XVIII, visto que respondia satisfatoriamente às necessidades sociais básicas de seu tempo.

A primeira grande transformação da universidade ocorrerá no século XVIII, com a soberania da racionalidade científica sobre a racionalidade filosófica e teológica, uma vez que a experimentação científica acaba com o dogmatismo do conhecimento fundado na metafísica. É bom lembrar que até esta época, os valores da modernidade estavam se desenvolvendo a margem das Universidades, pois estas estavam presas as suas tradições e resistiam aos novos desenvolvimentos científicos e filosóficos. É com o surgimento do Estado moderno que surge a universidade laica, declinando progressivamente a influência e a presença da Universidade Confessional, ligada à igreja.

A Universidade moderna, de fato, nasce com a universidade europeia. Segundo SERRÃO (1983), não se pode falar numa única universidade europeia, uma vez que ela assumiu contornos históricos e pedagógicos bastante distintos ${ }^{3}$ : a Medieval, definida pela essência

\footnotetext{
${ }^{3}$ Não detalharemos as características de tais modelos, uma vez que é ampla a bibliografia sobre o TEMA. Ver, por exemplo: KERR, 1982; RIBEIRO, 1982 e SPERANDIO, 1997.
} 
corporativa da instituição; a do Renascimento, caracterizada pelo tipo humanístico; a Moderna, conduzida pela filosofia das luzes e a Napoleônica, que privilegiou a formação técnica. Atualmente podemos falar de presença de quatro modelos em vigência, sendo três deles europeus - o inglês, o francês e o alemão - e um quarto modelo, que associa em alguma medida elementos do modelo europeu, que é o norte-americano.

A Universidade Inglesa é mais inspirada no tipo humanístico. Segundo RIBEIRO (1982), este modelo é tipicamente voltado para o ensino, principalmente para o ensino das elites. Visa formar o "homem elegante", de fino trato, com uma cultura geral e humanística, que possa ocupar posições de destaque na vida social, particularmente na vida pública. Embora atuem hoje na Inglaterra quase cinquenta universidades e um sem número de colleges, é ao conjunto "Oxbridge"4 que se referem os historiadores da Universidade ao tratarem do "modelo inglês". Optando inequivocamente pela educação, ocupou-se ele desde as origens com a formação da personalidade, do caráter, com forte acento moral, incorporando elementos do anglicanismo, religião oficial.

O modelo francês é também conhecido como napoleônico. Na lógica de seu governante, a moderna Universidade Francesa deveria enfatizar a formação de profissionais capacitados para o exercício dos cargos típicos da burocracia estatal. Em 15 de setembro de 1793, sob a alegação de que representavam a aristocracia e o Antigo Regime, as 22 universidades francesas foram suprimidas pela Revolução. Em seu lugar criaram-se cursos superiores à medida que eram necessários: em 1794, a Escola Politécnica e a Escola Normal Superior e, em 1802, já sob Napoleão, a Escola de Artilharia e Engenharia. Em $1^{\circ}$ de maio de 1806, Napoleão criou a "Universidade Imperial": uma corporação estatal de docentes que, tendo à frente um Grão-Mestre, destinava-se a manter o ensino secundário e superior exclusivamente público do Império.

A moderna Universidade Alemã tem a pesquisa como sua marca registrada, sendo mãe das universidades que temos hoje. Para vencer o descompasso entre as Academias Científicas e as Universidades tradicionais foi preciso criar uma Universidade diferente. Partindo da inovadora experiência da Universidade de Göttingen (1734) estruturada de modo a incluir em seus quadros os avanços científicos da época, Guilherme de Humboldt, diretor do Culto e da Instrução Pública do Ministério do Interior da Prússia, organizou e fundou, em 1810, a Universidade de Berlim como centro de liberdade acadêmica, onde se deveria buscar a verdade

\footnotetext{
${ }^{4}$ Tem como referências maiores as Universidades de Oxford e Cambridge, o conjunto "Oxbridge".
} 
através da pesquisa científica. O modelo humboldtiano marca a Universidade Moderna, na primeira década do século XIX, significando a primeira grande revolução na concepção de Universidade. Diferentemente do modelo inglês e francês, a pesquisa deveria prevalecer sobre o ensino embora houvesse uma preocupação muito acentuada em manter a indissociabilidade entre o ensino e a pesquisa.

Pesquisa e ensino são meios para o desenvolvimento do conhecimento e finalidade da universidade como geradora do "poder do saber" ou poder intelectual. A união do ensino com a pesquisa num clima de absoluta liberdade é o princípio básico que rege a universidade: só é possível ensinar livremente o docente que livremente pesquisa e só aprende livremente o aluno livremente associado à pesquisa do mestre. Juntamente com a Universidade de Berlin, nasce o que se convencionou chamar de "a universidade da pesquisa" associando o ensino à busca de novos conhecimentos, num movimento em que ensinar é menos reproduzir e mais conhecer o novo.

Já o modelo americano segue por outros caminhos, condizentes com a própria história da ocupação do "Novo Mundo". Em 1636, em Massachussets, tem-se a fundação de um College $^{5}$, que marcará o início da instituição universitária nos EUA. Como diz ROSSATO (1998, p.78), instituições de cunho religioso - eram mais propriamente seminários de formação de pastores do que "colleges" do tipo inglês - enfatizaram a educação geral e a formação do caráter, acentuando especialmente o aspecto moral. A expansão universitária nos Estados Unidos se ocorreu com rapidez espantosa a partir do século XVII, a ponto de já figurar, no século subsequente, como o primeiro país em número de universidades. Preservando características dos modelos inglês e alemão, foram, entretanto, adquirindo feições próprias, sob a poderosa e marcante influência do capitalismo. As universidades americanas, espelhando sua instrumentalidade aos interesses do capital, constroem um modelo de ensino e pesquisa intimamente articulado ao progresso econômico, do qual se tornam instrumento e guia.

ROSSATO (1998), em seu trabalho histórico sobre as universidades, mostrará como o modelo americano se expandirá, consolidando-se com as seguintes características ${ }^{6}$ :

\footnotetext{
5 Este primeiro "College" foi fundado em terreno doado por John Harvard marcou o início da instituição universitária nos Estados Unidos. A este se juntou, ainda antes da Revolução Americana, outros nove "Colleges" (William and Mary, Yale, New Jersey, Princeton, New York, Pensylvania, Brown e New Hampshire) raízes, todos eles de importantes e numerosas universidades estabelecidas após a independência.

${ }^{6}$ Esse conjunto de características são bastante elucidadoras do modelo americano, e merecem um estudo mais detalhado, pois representam, em muitos casos, sínteses das três experiências europeias. Mais detalhes em ROSSATO (1998).
} 
multiplicidade das instituições; diversidade; pragmatismo; pesquisa; democratização; integração com o grau inferior; tradição familiar ou grupal; mecenato e formação moral.

\section{O CASO BRASILEIRO}

No caso brasileiro, a história da universidade assume outro caráter. Derivado de um sistema colonial que vigorou de 1500 a 1808, com a vinda da família real, no Brasil, mesmo como escolas isoladas o ensino superior esteve proibido de se implantar, até 200 anos atrás. Isso se explica porque, na formação social escravista da colônia brasileira não cabia qualquer sistema de educação para a reprodução da qualificação da força de trabalho escrava. Muito pelo contrário, a ignorância, a superstição, o pavor do sobrenatural, eram condições para a submissão do escravo.

O complexo agroexportador movido pelo braço escravo que qualificava a formação social colonial dispensava qualquer forma de educação formal para habilitar sua força de trabalho ou para fornecer-lhe a ideologia a fim de reproduzir as relações de produção. Para o escravo, a pregação religiosa católica combinada com práticas religiosas que trazia da África, cumpria os requisitos ideológicos necessários para fundar e justificar seu lugar no processo produtivo. Mesmo os poucos trabalhadores livres, rurais e urbanos tinham sua qualificação reproduzida na produção e suas necessidades "espirituais" atendidas pela Igreja.

No topo da pirâmide social, a pequena e poderosa camada de proprietários e comerciantes, obtinha as primeiras letras obtidas no Brasil, em geral através de preceptores, e depois mandavam seus filhos estudar em Portugal. A escola jesuítica é parte da Igreja e as Aulas Régias atendem a determinações, em parte, superestruturais: a formação de uma "elite" para a dominação, para ocupar seu lugar na superestrutura, a qualificação da classe dominante e de seus agregados que iriam prosseguir os estudos em Coimbra. Daí a extrema lentidão de sua implantação, explicativa para o fato de chegarmos à Independência sem qualquer forma organizada de educação escolar.

A chegada da Corte Portuguesa em 1808 parece, à primeira vista, iluminar o território da colônia. Esse liberalismo, que chega com a Corte portuguesa, é assumido na forma específica que era possível no Brasil: esvaziado de seu conteúdo original e aplicado ao inverso. Isto é, não se pensava em reformar a estrutura econômica; garantiam-se as relações de produção 
escravistas, a grande propriedade rural e a estrutura colonial de produção e sua inserção no sistema colonial com tudo o que isto significava ${ }^{7}$.

Transferida a Corte para o Rio de Janeiro, as instituições criadas por D. João VI, no âmbito do que se pode chamar de ensino superior, estavam, na sua grande maioria, diretamente articuladas à preocupação com a defesa militar da colônia, tornada a sede do governo português. Ainda no ano de 1808, cria-se, no Rio de Janeiro, a Academia de Marinha, e, em 1810, a Academia Real Militar, para a formação de oficiais e de engenheiros civis e militares. Também em 1808, criaram-se os cursos de Anatomia e Cirurgia, para a formação de cirurgiões militares, que se instalaram, significativamente, no Hospital Militar (como também era o caso do curso da Bahia, citado anteriormente). A esses cursos, de início simples aulas ou cadeiras, acrescentaram-se, em 1809, os de Medicina e, em 1813, constituiu-se, a partir desses cursos, a Academia de Medicina e Cirurgia do Rio de Janeiro. Outros cursos foram ainda criados, na Bahia e no Rio de Janeiro, todos eles marcados pela mesma preocupação pragmática de criar uma infraestrutura que garantisse a sobrevivência da Corte na colônia, tornada Reino-Unido.

Além do caráter pragmático que marcava a quase totalidade dessas iniciativas, cumpre destacar também o seu caráter laico e estatal. De fato, essas instituições foram criadas por iniciativa da Corte portuguesa, e foram por ela mantidas, continuando a sê-lo pelos governos imperiais, após a independência política do Brasil em 1.822. Por sucessivas reorganizações, fragmentações e aglutinações, esses cursos criados por D. João VI dariam origem às escolas e faculdades profissionalizantes que vão constituir o conjunto das nossas instituições de ensino superior até a República. A esse conjunto, viriam se agregar os cursos jurídicos, criados apenas após a Independência, originariamente em São Paulo e Olinda, no ano de 1.827.

Foram poucas, entretanto, as iniciativas concretas dos governos imperiais no campo do ensino superior, limitando-se à manutenção das instituições existentes e à sua regulamentação. Além dos cursos jurídicos, instituídos por D. Pedro I, uma outra iniciativa importante seria a instalação, já no final do segundo Império, em 1875 - um ano depois da separação do curso de engenharia da Escola Militar, com a constituição da Escola Politécnica -, da Escola de Minas em Ouro Preto, à época capital da província de Minas Gerais.

\footnotetext{
${ }^{7}$ A esse mesmo respeito há um episódio extremamente ilustrativo. Quando, em 1808, a família real aportou, num primeiro momento, na Bahia, o comércio local se reuniu e deliberou solicitar ao Príncipe Regente a fundação de uma universidade literária, provendo para a construção do palácio real e o custeio da universidade importante soma de dinheiro. Essa solicitação, entretanto, não foi atendida e, por outro lado, o Príncipe decidiu criar um Curso de Cirurgia, Anatomia e Obstetrícia, em fevereiro desse ano, atendendo ao pedido do cirurgião-mor do Reino, José Correa Picanço, um dos portugueses brasileiros formados em Coimbra.
} 
No entanto, ao longo do Primeiro e do Segundo Impérios, a demanda pela constituição de uma universidade no país não desapareceu, sofrendo, porém, uma constante resistência por parte de distintos grupos, especialmente dos positivistas. Nada menos de 42 projetos de universidade são apresentados a essa época, sendo, entretanto, sistematicamente recusados pelo governo e pelo parlamento.

É preciso deter-se um pouco sobre as concepções subjacentes a algumas propostas encaminhadas contra ou a favor de uma universidade no país, pois a meu ver elas apontam para uma questão que é central para a própria sobrevivência dessa instituição e que hoje, mais do que nunca, se faz presente no âmbito do debate pedagógico.

Um dos projetos, no regime imperial, encaminhado por Justiniano José da Rocha à Assembleia Geral propunha a criação de uma universidade "para controlar todo o sistema de ensino, tanto o setor público quanto o privado, conforme o paradigma da Universidade de Paris, durante o governo de Napoleão". Desta maneira o que parecia justificar a proposta de criação dessa instituição era, primordialmente, a sua potencialidade como um instrumento de controle por parte do Estado sobre todo o ensino superior (além do seu caráter de universalidade, que também aparece na fala de Justiniano).

Parece-me também sugestivo que a resistência colocada pelos positivistas à ideia da criação de uma universidade no Brasil se fizesse justamente em nome da liberdade de ensino, princípio utilizado para advogar não só a retirada dos entraves legais que impediriam uma maior expansão da iniciativa privada no campo da educação (que, especialmente após 1870, começou a expandir-se no campo do ensino superior), mas também uma ciência livre de privilégios e da proteção do Estado, proteção esta que só serviria para profaná-la, nas palavras de Teixeira Mendes.

É significativa que, ao criar, em 1937, a Universidade do Brasil, Capanema atribuiria a esta nova instituição justamente a finalidade, talvez primordial, de controle e padronização do ensino superior no país. Tal questão remete, por um lado, à discussão sobre as finalidades dessa instituição e, por outro, para a complicada relação entre a universidade e o Estado, tendo em vista que uma das suas demandas essenciais, como instituição historicamente constituída, tem sido a de autonomia, particularmente acadêmica, com relação às demais instituições da sociedade e especificamente com relação ao Estado. Esta será uma questão central no debate que se travará sobre a universidade no Brasil ao longo dos anos de 1.920 a 1.940, quando de sua institucionalização efetiva entre nós. 
Como aponta MENDONÇA (2000:136-138) a experiência republicana é permeada por disputas entre modelos de universidade, os quais representam modelos e imaginários presentes entre as elites brasileiras. Segundo a autora,

"Os anos de instalação do novo regime viriam a propiciar um intenso debate sobre a questão da educação, no bojo da Constituinte, que, no entanto, arrefeceu-se rapidamente com a promulgação da Constituição outorgada e a consolidação de uma ordem política e social que se sustentava nas mesmas oligarquias regionais hegemônicas durante o Império, através da chamada política dos governadores. Apenas após 1920, quando essa ordem começaria a sofrer uma forte contestação por parte de distintos grupos e movimentos, nucleados em torno da bandeira da republicanização da República, esse debate seria retomado com força, num novo contexto, marcado pela ampliação decorrente do esforço de mobilização da opinião pública e pelo confronto entre diferentes projetos de construção/reconstrução da nacionalidade.

Anteriormente a essa época, a adoção do sistema federativo propiciou algumas iniciativas de criação de universidades em alguns estados. Essas universidades, entretanto, tiveram uma vida efêmera e, de fato, a primeira instituição que assumiu, entre nós, de forma duradoura, essa denominação foi a Universidade do Rio de Janeiro, criada em 1920, pelo governo federal (embora desde 1915 essa criação já estivesse autorizada), através da agregação de algumas escolas profissionais preexistentes. (p. 136)

Como apontam vários autores (CUNHA, 1980; FÁVERO, 1980 e MENDONÇA, 2000) os embates que ocorrem entre 1920 e 1950 podem ser analisados através de dois grandes projetos-sínteses, de Anísio Teixeira e de Fernando de Azevedo. Como aponta MENDONÇA:

“(....) dois documentos expressam de forma significativa as discussões que se desenvolveram nos últimos anos da década de 1920, particularmente sobre os rumos a serem atribuídos ao ensino superior. São eles os dois inquéritos promovidos, respectivamente, pelo jornal O Estado de S. Paulo, em 1926, e pela Associação Brasileira de Educação (ABE), em 1928.

Esses dois inquéritos são substantivamente diferentes entre si. O primeiro, conduzido por Fernando de Azevedo, acabava por referendar um determinado projeto de universidade (que se concretizou, em 1934, com a criação da Universidade de São Paulo). O segundo, embora também se propusesse à construção de um consenso em torno da questão da universidade, era muito mais representativo das diferentes concepções que atravessavam o debate em torno dessa questão e que se confrontavam no interior da própria associação. (MENDONÇA, 2000: 137)

Como dizia anteriormente, esses projetos representavam interesses fortemente estabelecidos no interior da classe dominante brasileira, ficando evidente que à essa altura o tema da universidade não atingia as camadas médias em fase de constituição e nem os segmentos populares. Com reação aos grupos representados, MENDONÇA (2000) indica que:

O primeiro grupo, liderado pelos católicos, valorizava especialmente o papel da escola secundária, como agência de homogeneização de uma cultura média, dentro de um projeto de recuperação do país de caráter moralizante que passava pelo resgate da tradição católica na formação da alma nacional. Para o segundo grupo, constituído basicamente por professores egressos da Escola Politécnica, a ênfase estava posta nas universidades que deveriam se constituir em verdadeiras usinas mentais, onde se formariam as elites para pensar o Brasil (equacionar os problemas magnos da nacionalidade) e produzir o conhecimento indispensável ao progresso técnico e científico. Para esse grupo não era a tradição o cimento da unidade nacional, mas todo 
um conjunto de medidas de integração nacional, decorrentes da expansão do progresso. Dessa perspectiva, esse grupo defendia a criação de Faculdades de Ciências voltadas para a pesquisa científica pura ou desinteressada. (MENDONÇA, 2000: 137)

Particularmente este segundo grupo não se sentiu atendido com a Reforma Campos, de 1931, que se materializa no chamado Estatuto das Universidades Brasileiras traz a marca da ambiguidade, decorrência do caráter conciliatório do projeto governamental.

“É o próprio Campos, então Ministro da Educação, aliás, quem afirma que o seu projeto representa um estado de equilíbrio entre tendências opostas, de todas consubstanciando os elementos de possível assimilação pelo meio nacional. A principal inovação prevista no Estatuto era a possibilidade (e não a obrigatoriedade) de incluir entre as escolas que iriam compor a universidade uma Faculdade de Educação, Ciências e Letras, instituição meio híbrida, que deveria se constituir, por um lado, em um órgão de alta cultura ou de ciência pura e desinteressada, e, por outro, ser, antes de tudo e eminentemente, um Instituto de Educação, destinado a formar professores especialmente para o ensino normal e secundário. A justificativa para esse caráter híbrido estava em que era preciso ter cautela e, ao se instalar pela primeira vez no país um Instituto de Alta Cultura, essa instituição não poderia ser organizada de uma vez e de forma exclusiva (apud Fávero, 1980, anexo I, p. 132-133). Esse mesmo argumento era usado para justificar a tutela que se estabelecia, por parte do governo federal, sobre as instituições de ensino superior.

No entanto, no interior da ABE, travava-se uma luta pelo controle da entidade entre os católicos e um novo grupo que acabaria por assumir a sua direção, constituído pelos intelectuais que vieram a ser conhecidos como os Pioneiros da Educação Nova e que, em 1932, lançaram o seu Manifesto ao Povo e ao Governo, onde explicitavam o seu programa de reforma da educação, que incluía a criação de verdadeiras universidades. (MENDONÇA, 2000: 138)

Aparece, aqui, a tridimensionalidade da universidade: produzir ciência, transmitir conhecimentos aos educandos e divulgar, à sociedade, o conhecimento produzido.

\begin{abstract}
"Defende-se a centralidade da pesquisa, como "sistema nervoso da Universidade, que estimula e domina qualquer outra função" (idem, ibidem, p. 75), assumindo a crítica às instituições de ensino superior existentes no Brasil, que nunca teriam ultrapassado os limites e as ambições da formação profissional. Nessa instituição seriam formadas as elites de pensadores, sábios, cientistas, técnicos e os educadores - aí entendidos os professores para todos os graus de ensino. (MENDONÇA, 2000: 138)
\end{abstract}

Em linhas gerais, essa foi a concepção que informou as duas experiências universitárias desenvolvidas ao longo desses anos por iniciativa de educadores vinculados ao grupo dos renovadores, a saber, a Universidade de São Paulo (USP), criada em 1934, pelo grupo de intelectuais que se articulava em torno ao jornal O Estado de S. Paulo, entre os quais Fernando de Azevedo, e a Universidade do Distrito Federal (UDF), criada por Anísio Teixeira em 1935, no bojo da reforma de ensino por ele empreendida, como secretário de Educação, no Rio de Janeiro. Tanto no caso da USP, quanto no da UDF, a preocupação com o desenvolvimento da pesquisa e dos altos estudos é central. 
Esse é o modelo ainda vigente nas universidades públicas brasileiras e que permite criar, na década de 1.950, condições para o desenvolvimento da pós-graduação e que sobrevive até hoje, passando praticamente ileso pelo regime militar (1964-1985). Tem como características elementos de permanência que estão no cerne da universidade brasileira e que formam o núcleo de imaginários que se mantêm, a saber: a) uma noção de que a universidade é uma instituição social construída por e para as elites; b) a constatação de que o discurso universalista e universalizante, cerne do conceito de universidade, é incompatível com a história colonial e imperial brasileira, cujo conceito dominante de educação, como vimos, era altamente excludente e pragmática com forte viés instrumentalista e profissionalizante.

No entanto, à medida que o país se urbaniza e penetra numa economia de mercado e numa sociedade de massas, o conceito de universidade, como vimos, se modifica, aproximando-se, cada vez mais, dos conceitos universais de universidade pelo mecanismo meritocrático de seleção. Tais constatações permitem-nos, neste início do século XXI, trazer outros temas, como o da universidade para a inclusão social, como central.

\section{HUMANIDADES E UNIVERSIDADE}

Encerro aqui a discussão histórica, passando a analisar a questão desta sessão: “Os lugares da pesquisa e do ensino nas Humanidades no século XXI". Retomo a provocação de Pedro Demo, destacando que este autor mesmo tempo em que faz uma crítica à estrutura vigente; aponta a necessidade de uma relação mais linear entre educandos e educadores, destaca também a pesquisa como fio condutor para este processo; enfatiza os espaços múltiplos de produção de informações e conhecimentos, com as novas tecnologias e a realidade virtual penetrando as nossas práticas cotidianas de ensino e pesquisa.

Este discurso a que recorro, pela sua generalidade, pode ser acatado por todas as áreas de Conhecimento, mas me interessa aqui é refletir como isso se desdobre nas Humanidades, retomando a indissociabilidade já apontada na nossa Constituição e que é também a bandeira de luta que orienta as nossas práticas e nas nossas reivindicações acadêmicas, científicas, trabalhistas e políticas.

Comecemos por delimitar que pertence a ela: as artes, a literatura, a filosofia, as ciências sociais e políticas, a história e mesmo também o direito, a psicologia e a antropologia. Aqui podemos incluir também a economia. 
Entendemos que a ação das humanidades no conjunto da produção científica está na possibilidade de uma formação horizontal para o saber, saber fazer, comportar-se e fazer ser. Mas de forma alguma desarticulada das demais áreas do conhecimento.

Recorremos aqui à discussão de Marilena Chauí, num artigo provocador intitulado "as humanidades contra o humanismo", em que analisa a crise - longa por sinal - da USP, destacando em sua análise a extrema similaridade entre os documentos do Banco Interamericano de Desenvolvimento-BID, da Lei de Diretrizes e Bases da Educação-LDB, notadamente nas suas leis complementares que trata, da Educação Superior, dos documentos da reitoria da Universidade de São Paulo-USP e mesmo dos da Faculdade de Filosofia, Ciências e Letras desta universidade. Todos, sem exceção, avaliam a universidade a partir de alguns eixos:

- $\quad$ custo-benefício, em que apontam que a universidade tem um custo muito alto para um pequeno benefício;

- $\quad$ outro eixo é o da inoperância, apontando primeiro que a qualidade do ensino e da pesquisa é considerada baixa; a segunda prova da inoperância é o alto índice de evasão; o terceiro é o alto custo com pessoal, isto é com os docentes e técnicos e o consequente pouco investimento em infraestrutura.

- o BID ainda destaca, como corolário dos dois primeiros - custo-benefício e inoperância, é a incapacidade de as universidades latino-americanas em enfrentar a questão da "recompensa-punição", ou seja, não conseguimos, por este diagnóstico, criar um bom sistema de recompensas pela produtividade e de punição pela improdutividade. O que se oculta neste tipo de diagnóstico é uma profunda desconfiança do modelo de universidade que adotamos.

Mas o que tanto Chauí (2001) como Demo (2005) trazem à luz, neste cenário, que podem ser balizadores da nossa discussão aqui, neste evento?

Em primeiro lugar, é preciso contextualizar que a nossa universidade, como qualquer outra instituição social, está inserida na "forma contemporânea do capitalismo, convencionalmente denominado de neoliberalismo, que tem como peculiaridade reduzir a política a simples mecanismos econômicos, não à operação geral das forças econômicas" (Chauí, 2001:1).

Explicando melhor esta afirmativa, Chauí afirma que:

Isso significa que ocorre a redução do político aos mecanismos diretos da economia, reduzir a economia à finança com o jogo do mercado e considera-lo: primeiro, o ponto final da história humana; segundo, a fatalidade como se não houvesse outro caminho, 
ele é a fatalidade necessária; e terceiro, como consequência, naturalizar a situação contemporânea do capitalismo de tal maneira que a desestruturação que esse modo de funcionamento do capital provocou, que ele produziu, no interior da luta de classes com respeito às formas de organização e referências da classe trabalhadora, também sejam naturalizadas.

Essa postura consiste em fazer com que o jogo do mercado seja considerado a última ratio, ou seja, o fundamento de toda a racionalidade. (...) O mercado, portanto, se tornou não só o fim da história, a fatalidade humana e a naturalização das relações sociais, mas também o cerne onde se decide o que é racional e o que é irracional. A consequência disso, e que transparece nas questões que vamos colocar a respeito da universidade, é o fechamento da ideia de que as coisas podem ser diferentes, que precisam ser diferentes e que devem ser diferentes. Fica ocultado que o mercado, e o seu funcionamento, é uma instituição produzida pela ação dos homens e que pode ser desfeita por ela. Desaparece, portanto, a ideia de uma outra realidade possível construída por nós mesmos. (CHAUI, 2001: 2)

Se o neoliberalismo, como doutrina, ideologia ou a forma contemporânea de expressão do capitalismo se estende, de forma global sobre o planeta, devemos refletir um pouco sobre centralidade que adquire as relações econômicas que reduz tudo a uma questão de mercado (capacidade de produzir e de consumir) e que neste cenário o neoliberalismo não está interessado num conjunto de disciplinas que denominamos Humanidades ou as ciências do espírito ou do pensamento.

Mas em que pese este pensamento único, sigo as reflexões de Chauí, colocando como um de nossos pressupostos para a reflexão: porque todas as questões relativas à Universidade têm que girar sempre em torno das relações delas com o mercado? Defendo que é das Humanidades que depende nossa visão de mundo, a nossa representação social e verbal da realidade. Ao invés de lamentar, temos que buscar superar a máxima de que Humanidades e neoliberalismo se opõem.

No entanto, não podemos ser ingênuos e ignorar que a questão problemática da “invasão" da leitura neoliberal na educação é que houve uma "migração" das tomadas de decisão sobre os assuntos educacionais e culturais para organismos internacionais, quer diretamente, através de fomentos e tratados, quer de forma mais sutil e indireta, através do financiamento da formação de futuros gestores, domesticados por esta ideologia.

Isso não é novo!

Não é por acaso de vários organismos e governos seguem a cartilha de Veblen, que escreveu na virada do XIX para o XX a obra "Teoria da classe ociosa", na qual afirma que as humanidades se constituía em uma atividade inútil da classe parasitária. Afirmava ainda que as humanidades são, do ponto de vista da eficiência econômica, estéreis anacronismos e que as línguas clássicas são substancialmente inúteis. 
Chauí (2001), em sua análise nos indica que a harmonia, sintonia e identidade desses três discursos presentes nos documentos oficiais - quer dos organismos multilaterais quer os do próprio MEC - indica a penetração da doutrina liberal, isto é, são expressões da noção do pensamento único ou pensamento hegemônico. Os documentos analisados expressam,

[...] com muita clareza, no caso do Brasil, uma verdadeira experiência de hegemonia que se apresenta da seguinte maneira: há um consenso sociopolítico e um dissenso inteiramente difuso, sem rosto, sem força, sem organização e sem poder. E, portanto, não temos várias posições a respeito de problemas. Temos uma que diz o que a coisa é e porque que é assim, e uma multidão completamente dispersa que diz: "acho que não é assim", fica por isso mesmo. É esta a situação que estamos experimentando. (CHAUÍ, 2001:3)

O que quero lembrar, a despeito das nossas convicções e leituras sobre a universidade, é que ela já nasce como fruto de um pacto das elites, para seu uso e interesses. Paradoxalmente, neste momento as Humanidades assumem um lugar importante, com as Faculdades de Filosofia e os Institutos de Educação assumindo a dupla função da formação de professores e da preparação para a alta cultura, enquanto o Direito segue, mesmo neste espectro, com o seu papel de profissão imperial, formando a classe política para as direções do Estado.

\section{MARCAS DO NEOLIBERALISMO - A PROFUNDA SEGMENTAÇÃO DAS HUMANIDADES PELA LÓGICA DO MERCADO}

A partir deste momento encerro a discussão mais acadêmica e trago algumas reflexões a partir da minha vivência como gestora na Universidade Federal do Paraná. Como diretora do Setor de Ciências Humanas, Letras e Artes: nosso curso de Letras é um dos criados na fundação da Faculdade de Filosofia, Ciências e Letras, em 1938 e, juntamente com o curso de História, formam o grupo de maior tradição no ensino e na pesquisa. Já havia instalado no seio do curso a discussão sobre a possibilidade de criação de um outro modelo de graduação, muito mais vinculada ao ensino de línguas, com currículo enxuto, adaptado às necessidades do mercado. Com a adesão da UFPR ao Programa de Reestruturação e Expansão das Universidades-REUNI, e a discussão caminhou para uma proposta de divisão das Letras. O tema incendiou o curso e os demais vinculados ao $\operatorname{Setor}^{8}$ e foi objeto de discussões, assembleias, manifestações a favor e contra. Grosso modo, a proposta segue algumas já implantadas também com os recursos do

\footnotetext{
${ }^{8}$ Não foram só estes cursos que foram propostos, mas também a segmentação das Ciências Sociais em dois ou três cursos, da Comunicação Social e do Design. Ou seja, a possibilidade de recursos acoplados a primeiro, novos cursos e, depois, novas vagas, exacerbou movimentos separatistas no seio de cursos tradicionais.
} 
REUNI, tendo como referência experiências desenvolvidas em universidades argentinas e chilenas. Depois de muitos embates, em que as propostas instrumentais e mercadológicas ficaram cada vez mais explícitas, o projeto foi abortado. Paradoxalmente, todas as propostas de criação de cursos noturnos para as Licenciaturas e/ou ampliação de vagas foram muito combatidas.

Na UFPR vivemos esta permanente tensão, no sentido de criar cursos mais utilitaristas, de adesão às necessidades do mercado, com formação mais curta. Só não se prospera devido às lutas sindicais da categoria docente, bem como à estrutura de contratação de professores pela via do concurso e pela noção de estabilidade, que impede a renovação do quadro docente à cada demanda do mercado. Se isso freia, por um lado os projetos de adesão direta da universidade ao mercado, por outro trava a mesma para novos modelos de formação e de inserção de profissionais na estrutura docente.

Saindo do exemplo prático e retomando a reflexão podemos afirmar que o capitalismo avançado tem como norte transformar as universidades em "instalações de adestramento técnico ou em institutos de pesquisas corporativas", eliminando na raiz as disciplinas humanísticas. Este capitalismo corporativo está mais interessado nos negócios de uns poucos do que numa educação e formação democrática. Substitui o discurso da diversidade, da pluralidade política e da alteridade - base da noção moderna de democracia - pelo discurso da eficiência, da competitividade, da rentabilidade pela prestação de contas, esquecendo-se que não são discursos antagônicos, uma vez que a riqueza das Humanidades está na possibilidade de uma formação horizontal para o saber, saber fazer, comportar-se e fazer ser.

Para países com alta desigualdade social como o Brasil, este discurso tecnocrático assume uma complexidade que por um lado prima por um aligeiramento da formação, por se concentrar nos aspectos técnicos - exemplo das experiências dos curso pós-médio, tecnólogos ganhando espaço sobre as formações de longa duração - que impacta pesadamente a formação de professores e retira cada vez mais os recursos (parcos) das áreas humanísticas, em nome da necessidade de formação maciça e rápida de mão de obra para o mercado em constante mudança,. Por outro, promove uma verdadeira fratura num corpo ainda em formação - a massificação e democratização do ensino superior - que por mais virtuoso seja este processo perde-se a oportunidade de formar cidadãos e não apenas técnicos, pessoas que não apenas saiba fazer como, e principalmente, saibam ser e comportar-se num ambiente plural e multicultural. 
Outro aspecto que merece reflexão é a estandardização e massificação do ensino para as camadas mais pobres - seja cursos de curta duração presenciais, seja a formação on line, que hoje movimentam fortunas através de universidades que são empreendimentos multinacionais. A presença das máquinas privadas de produção de ensino - veja-se o fechamento dos cursos de História, Filosofia e Ciências Sociais, por um lado, e a diminuição do curso de Pedagogia ${ }^{9}$ de cinco para três anos em muitas delas - configura um processo de "estandardização do vulgar". Assim, as Humanidades continuam a ser retiradas da formação acadêmica, assentada na falsa ideia de eficiência, mas apenas que é essencialmente técnica.

\title{
COMO PENSAR O FUTURO?
}

A combinação analítica entre os modelos anteriormente descritos, com a experiência brasileira nos leva a pensar que universidade está sendo construída pela sociedade brasileira, a quem ela serve e que imagem projeta de si para os cidadãos. Que configuração assumirão a pesquisa e o ensino nas Humanidades neste século, com a influência da microeletrônica, sob o signo da globalização e com a vertiginosa aceleração técnico-científica?

Se temos que lidar tanto com a tradição do conhecimento como com as mudanças exigidas pelas questões do século XXI, lembramos de Marcovitch (1998:23) que, ao falar do motivo da existência da universidade diz que: "ela é o melhor lugar possível para uma enriquecedora transição da adolescência para a juventude e, depois, para a idade adulta" e completa: "A universidade tem ainda o papel de formar a cidadania. Cabe-lhe, e talvez seja essa a sua principal função, desenvolver a inquietude do ser social". Continua ele:

\begin{abstract}
O que fazer para suplantar as ideias individualistas e egoístas tão presentes em nosso meio hoje? Como unir todas essas ansiedades latentes em torno de um objetivo coletivo? Uma das possíveis respostas estará na interdisciplinaridade, que é a capacidade de diálogo entre cientistas, provenientes de horizontes diversos trabalhando sobre um tema comum. E cada um contribuindo com sua metodologia específica de sua matéria. E esta capacidade de compreender os outros, e através disto, se questionar será fator determinante na adoção desse sistema, que terá impacto significativo na estrutura acadêmica, e seus efeitos se alastrarão sobre os cursos de graduação e pós-graduação, pesquisa e extensão. Entretanto, para isto acontecer será necessário repensar os programas pedagógicos dos cursos, as relações professor/aluno, um novo enfoque para as relações universidade e sociedade sobre uma perspectiva mais dinâmica e participativa, enfim uma maior integração em todos
\end{abstract}

\footnotetext{
${ }^{9}$ Tenho ouvido de estudantes e professores de faculdades particulares que, para muitas famílias com carências econômicas, a combinação da possibilidade de acesso ao ensino superior privado pelos mecanismos de financiamento público colocados à disposição dos alunos, por um lado e, por outro o cálculo econômico de que é mais interessante para a família fazer um esforço adicional para pagar um curso privado por três anos ao invés de investir cinco aos num curso público, tem pesado também a favor da busca pelo ensino privado. No entanto, isso carece de melhor investigação.
} 
os âmbitos, mas o principal, a universidade estará contribuindo para a formação de indivíduos polivalentes com uma visão global, rompendo de vez com a cultura fragmentada. (MARCOVITCH, 1998:23)

Para tanto ela terá que abandonar a forma tradicional de ensino, pesquisa e extensão, além de vencer os obstáculos daqueles que se recusam a aceitar inovações e preferem o conformismo. Dito de outra forma, ou a instituição universitária começa a pensar de forma interdisciplinar ou ela estará de costas para o futuro.

Retomamos a provocação de Pedro Demo, utilizada no início desta minha exposição: o quanto realmente, como parte de uma instituição social entrelaçada com interesses corporativos, ideologias políticas diversificadas (usando uma linguagem anacrônica, como espaço de disputas entre a direita e a esquerda, entre projetos meritocráticos e os emancipadores) a universidade e mais particularmente as Humanidades podem projetar seu futuro neste quadro de neoliberalismo, em escala mundial e de uma guinada ao conservantismo, no caso brasileiro?

Vou tentar apontar, à guisa de uma agenda de debates, os seguintes pontos:

1 - Sobre a questão do financiamento: não há equilíbrio entre as Humanidades e a área de Ciência \& Tecnologia, pois esta última sempre tem maiores possibilidades de obter recursos, dentro e fora da universidade. As agências de fomento, nesta quadra histórica, estão claramente priorizando projetos ligados à genômica e à tecnologia de informação. Precisamos criar, no espaço universitário formas de diferenciadas para os pesquisadores das Humanidades, além de outras medidas que ampliem o seu potencial de captação de recursos. O desafio é superar nossa dificuldade, muitas vezes nosso desinteresse em dominar as regras do jogo e com isso, reafirmarmos o pensamento corrente que somos inaptos para dominar a correta estruturação de um projeto, que inclui rígidos cronogramas físicos e financeiros a cumprir.

Acompanhei vários processos de construção de projetos integrados, multiusuários, preparados por pesquisadores da universidade, sob orientação da área de pesquisa, que compõem os projetos PROINFRA que devem ser apresentados ao CNPq e FINEP, assim como aqueles submetidos a editais para financiamento a partir dos fundos setoriais. Em todos os casos há uma enorme dificuldade de as Humanidades em delimitar suas propostas, que vai desde 'fazer caber no número de caracteres", passando pela justificativa de viabilidade acadêmica e econômica, pela definição da infraestrutura necessária até a preparação de um memorial descritivo. Se os professores agem assim, é por que temos muita resistência em aprender a lidar com a nova figura do "professor empreendedor" e, consequentemente, em pensar em iniciação 
para o empreendedorismo ou numa linguagem mais nossa, de inserir disciplinas de elaboração de projetos e captação de recursos nos currículos de graduação e pós-graduação.

2 - Novos desenhos curriculares. Por que não enfrentamos este desafio? A universidade embora fale na indissociabilidade entre ensino-pesquisa-extensão, de fato só a entende se houver a obediência do passo a passo em que a extensão aparece como "prima pobre”. A experiência pedagógica desenvolvida no Setor Litoral da UFPR, com o ensino centrado em projetos de intervenção na realidade litorânea, quando a centralidade se deslocou para a extensão - no sentido de se fazer uma formação dos estudantes a partir de situações problemas do meio em que se inserem e dali organizar o plano de estudos, invertendo a ordem sempre alardeada, foi objeto de imensa desconfiança interna. Mesmo que tenham sido muito bem avaliados pelo MEC e reconhecidos pela comunidade acadêmica nacional e internacional, a proposta sofreu todo tipo de erosão interna. Passados dez anos e um intenso bombardeio ao PPP, o projeto ainda segue com este princípio, mas desfigurado.

3 - Para tratar da relação com o mundo externo, apoio-me na reflexão de Jacques Marcovitch, quando reitor da USP:

\begin{abstract}
Devemos não apenas contemplar a escola, mas o ambiente externo. Há, do lado de fora, um mundo pouco receptivo à contribuição de filósofos, historiadores, sociólogos e outros especialistas formados pelas Humanidades e que têm a academia como espaço quase único de trabalho. Além do campus, um ambiente pragmático e dominado pela mais dura materialidade prefere os egressos das escolas profissionalizantes. Ocorre que lá fora não existe apenas a demanda empresarial. Existe o Estado. E o espaço do Estado, que tantos querem mínimo, não pode encolherse a ponto de não abrigar estudiosos que são fundamentais no equacionamento de políticas públicas. E cabe às academias, em seu diálogo com os governos, alertá-los para este aspecto da crise das Humanidades. Se esta elite intelectual, permanentemente debruçada sobre os problemas sociais, não decifrar o seu enigma, quem o fará? Não será certamente a tecnoburocracia com a sua visão nublada pelo viés político-partidário. Tampouco a mídia, com a sua abordagem imediatista, centrada no quadro aparente, sem buscar nuances, causas, raízes e fatores somente percebidos pelos que fazem desta problemática um objeto permanente de estudos. (MARCOVITCH, 2002: 235)
\end{abstract}

Coloco assim a questão: Em que medida nossos cursos e nós como professorespesquisadores estamos voltados para o mercado? Entendo mercado como as demandas do setor empresarial, da sociedade civil nas suas diversas organizações, e do Estado, como ambiente privilegiado para nossa atuação. As licenciaturas - enquanto uma área de atuação na política educacional terra a terra - tem sido a que privilegiamos. Mas será que estamos incentivando nossos orientando, quer nos trabalhos de conclusão de cursos, nas dissertações e teses, a enfrentarem o desafio das observações participantes e das devolutivas de resultados que os comitês de éticas e agências governamentais impõem como condição para acesso às fontes? A 
minha provocação vai no sentido de é preciso assumir a posição de protagonistas -mesmo com os riscos de sermos taxados de militantes - na proposição de estudos; no acesso às informações disponíveis nos documentos e arquivos em nível municipal e estadual.

4 - Temos que ser mais incisivos na constituição de grupos interdisciplinares dentro da própria universidade, demarcando que qualquer estudo nas áreas de políticas públicas exige a sua formulação pela comunidade epistêmica- das quais as Humanidades devem ter sempre um assento garantido: qualquer estudo sobre estratégias do Estado moderno para a saúde, educação, defesa do meio ambiente, trabalho, segurança ou qualquer outra demanda social, é indispensável o concurso das Humanidades, tendo em vista a sua noção abrangente do conjunto da sociedade e das suas carências principais. Isso tem que valer tanto para dentro da universidade, como para o espaço em que ela se localiza. A minha pergunta é: estamos abertos para isso, estamos dispostos a abandonar nossa alta especialização por uma ação mais interdisciplinar e para o diálogo com as "ciências duras", por exemplo? Como membro do Comitê de Pesquisa do Setor de Humanas o que verifico é uma duplicação de projetos com temas afins, mas completamente individualizados. O professor do curso A, com um projeto $\mathrm{X}$, não dialoga com o professor do curso $\mathrm{B}$, com projeto muito similar. $\mathrm{O}$ mesmo ocorre em investigações com objetivos iguais, mas com abordagens teóricas distintas. Pouco se avança nos estudos comparativos.

5 - Sobre a questão da inserção e produção internacional. Defendo e acho que ainda temos muito a andar neste sentido, mas minha experiência no Pós-doutorado na Europa me mostrou que nas áreas de Sociologia, de Antropologia e Ciência Política, por exemplo, temos uma diversidade de objetos e consequentemente um maior desafio de explicações do que eles. Outro aspecto é uma certa postura colonizada, que nos faz importar teorias explicativas construídas a partir de realidades diferentes da nossa. Ex. nas Humanidades é a importação, in totum de autores como Bourdieu.

Continuamos mirando o mundo eurocêntrico e abandonamos o diálogo Sul-SUL. A produção latinoamericana e mesmo o que se produz em África, Índia e Europa do Leste fica para segundo plano.

6 - Sobre o fortalecimento dos estudos micro e mesorregionais. No Paraná há sete universidades estaduais e quatro federais e temos muita dificuldade em produzir estudos comparados - de base mais local - para adensarmos conhecimento da nossa realidade. Meu desafio é vencer a Síndrome da $5^{\mathrm{a}}$ Comarca. 


\section{7 - Sobre a inserção na discussão sobre o cotidiano da sociedade brasileira. Quando} vice-reitora e depois como diretora do Setor de Humanas, gastava um bom número de horas semanais no trabalho de convencimento dos nossos professores a participarem dos debates colocados tanto por grupos organizados, como os da mídia. Muitos professores com livros e artigos sobre o assunto, com inserção até internacional, recusam-se a opinar e se colocar publicamente. Depois reclamavam quando os não especialistas se colocavam falando de todos os assuntos. Sigo aqui um princípio da Física: não existe espaço vazio, ou ocupamos ou outros o fazem, com qualidade lamentável.

8 - O retorno aos grandes temas que são nossos valores mais caros: universalismo, fraternidade, direitos compartilhados, combate à exclusão e ao obscurantismo. Como fazer isso? Entendo que temos obrigação de agir como comunidade de especialistas nos temas que envolvem as Humanidades: na questão ambiental, sobre trabalho, sobre a herança colonial e autoritária brasileira, sobre os povos ancestrais, sobre novas formas de consumo, sobre as novas linguagens, sobre tendências musicais, sobre a multiplicidade de manifestações culturais, sobre comportamento, sobre a crise urbana, sobre a expansão do agronegócio, sobre felicidade e a ética, por exemplo. Como área, podemos também propor à universidade, aos governos municipais, aos órgãos estaduais, parcerias em grupos de pesquisa sobre políticas públicas, buscando levantar indicadores e diagnósticos, oferecendo propostas nas áreas de educação, saúde, cultura, representação política e meios de comunicação que dizem respeito aos interesses da comunidade afro-brasileira, da população indígena, da questão da mulher, dos jovens, comunidade LGBT, sobre os novos arranjos familiares, sobre nosso passado histórico, sobre arqueologia, sobre a violência do Estado e a familiar, por exemplo, sobre a repressão entre tantos outros.

9 - Como lidar com os organismos multilaterais. Com a ação crescente dos organismos multilaterais - BID, UNESCO, OIT, CEE, OCDE, por exemplo - que nos oferecem financiamentos como contrapartida à execução de suas agendas de pesquisa, precisamos ter uma atitude menos colonialista no sentido da defesa de nossa produção intelectual. Muitas vezes estas missões visam a uma apropriação da nossa experiência e resultados de investigação e, se não queremos o insulamento, é necessária uma atitude mais negocial. Em tempos de globalização, é preciso achar um ponto de equilíbrio entre a submissão deslumbrada e o nacionalismo xenófobo. Aqui eu defendo fóruns de direções setoriais das Humanidades, para que possamos pensar em agendas setoriais (por universidade) e agendas regionais de incentivo às pesquisas. Não significa desmontar os espaços de autonomia de cada pesquisador e de seus 
grupos de pesquisa, mas buscar aglutinar forças em projetos de ossatura mais densa, para disputas de recursos em nível nacional e internacional.

10 - Ainda nos desafios para os próximos anos estão, por um lado, o enfrentamento dos movimentos separatistas e os fundamentalismos que se espalham; por outro, não podemos nos abater pelo pessimista e devemos enfrentar os frutos do progresso e a sua forma desigual de distribuição: novos temas se apresentam para as Humanidades como o do envelhecimento da população brasileira e mundial, o prolongamento da juventude, a crise do emprego e as novas formas de empreendedorismo que surgem. Aqui há um desafio que somos os principais interlocutores: como conciliar os benefícios da globalização com a coesão social? Como assegurar a empregabilidade? Essas respostas somente poderão ser dadas pelas Ciências Humanas.

11 - Sobre os mecanismos de avaliação: devemos ocupar, do ponto de vista de uma política acadêmica, devemos agir coletivamente para que haja valorização da produção gerada a partir dos projetos com as comunidades (extensão), desenvolvimento de metodologias de intervenção, e aqueles de veiculação local. Aqui defendo uma atuação mais forte nos espaços, quer de financiamento - Fundação Araucária - articulação com organismos regionais (ex. do que faz a área de economia com o BRDE). Aqui, imagino uma estrutura modulada, que nos permita manter os critérios das publicações indexadas que garantem nosso espaço nacional e internacional, com uma que contabilize a produção voltada à reflexão e intervenção em realidades locais.

Tenho ainda algumas reflexões sobre o ensino:

12 - Pensar no reforço das licenciaturas como espaço de preparação para o ensino na Educação Básica, aumentando a parte experimental junto às escolas públicas. Aumentar as bolsas para iniciação docente, pontuando de forma igual, nos processos de progressão que as IC. Aumentar os projetos de extensão, enfatizando aqueles de caráter intersetorial voltados à realidade escolar, das crianças e dos jovens.

13 - Experimentar, em sala de aula, o uso dos aplicativos dos celulares como coadjuvantes no processo de pesquisa e reflexão.

14 - Ouvir mais as linguagens corporais, as falas e as expressão dos jovens nas escolas, trabalhando com os professores da rede pública em rodas de conversas etc. Desenvolver pesquisas qualitativas de forma a propiciar uma maior compreensão do mundo juvenil e seus desafios. 
15 - Trabalhar mais a noção de uma governança cooperativa nos cursos, privilegiando atividades complementares voltadas ao trabalho comunitário, às intervenções na realidade local e ao voluntariado. Passar da discussão teóricas sobre equidade e igualdade para as práticas colaborativas professor-professor; professor-técnico e professor-estudantes. Dou ênfase aqui no professor pois é ele que detém o protagonismo na situação de sala de aula.

Enfim, esta é uma pauta aberta, inconclusiva, como é o nosso fazer na Universidade. Como últimas palavras só posso dizer que devemos manter a mente aberta às novas explicações do mundo, às novas formas de relações que se estabelecem pelo uso da tecnologia e pela globalização, mas sem perder a essência das relações sociais. Devemos cultivar a capacidade de ouvir, de enxergar e de dialogar com todos, desde aquele que está ao nosso lado no dia-adia, até o Outro, de países com culturas e referências distantes. Para mim, este é o lugar, inegociável, das Humanidades neste século.

Muito obrigada!

\section{REFERÊNCIAS}

BAETA NEVES, Clarissa Eckert. (2007) Desafios da educação superior. In: Sociologias, Porto Alegre, ano 9, $\mathrm{n}^{\circ}$ 17, jan/jun, p. 14-21

BERCHEM, Theodor. (1990) A missão das universidades na formação e no desenvolvimento culturais: a diversidade dentro da universalidade. Cadernos Plurais (Série Universidade - I). Rio de Janeiro: Editora da UERJ, setembro.

BERTONHA, João Fábio. Modelo americano ou europeu: qual o melhor caminho para a Universidade brasileira? Retirado de www.espacoacademico.com.br/014/4bert/htm. Acesso: 23 de janeiro de 2008.

BORRERO, C. A. (1993) Simposio permanente sobre la Universidad. Bogotá: ASCUN, IFES, ICFES. v. 12 a 16.

CUNHA, Luiz Antonio. (1980) A universidade temporã. 2. ed., Rio de Janeiro; Editora Civilização Brasileira.

CHARLE, Christophe; VERGER, Jaques. (1996) História das Universidades. São Paulo: Editora da UNESP.

CHAUI, Marilene. (2001) As humanidades contra o humanismo. In: SANTOS, Gislene (org.)

Universidade, Formação, Cidadania. Ed. Cortez, 15_32. Versão LATEX: 2011 may31. http://angg.twu.net/LATEX/chaui-hch.pdf; http://angg.twu.net/LATEX/chaui-hch.tex.html; http://angg.twu.net/SCANS/univ_form_cid/hch_e_rinesi.pdf

CHERVEL, André; COMPÈRE, Marie-Madeleine. (1999) As humanidades no ensino. Educação e Pesquisa, São Paulo, v. 25, n. 2, p. 149-170, jul/dez.

DEMO, Pedro. (2006) Ensino Superior no Século XXI: Direito de Aprender. In: Reflexões PUCRS, Bento Gonçalves, 1-59, maio. 
FAVERO, Maria de Lourdes de A. (2006) A universidade no Brasil: das origens à Reforma universitária de 1968. EDUCAR, Curitiba, n. 28, Editora da UFPR.

. (1980) Universidade e poder. Rio de Janeiro, Achiamé.

HALBWACHS, Maurice. (2004) A memória coletiva. São Paulo: Centauro.

KERR, Clark. (1982) Os usos da Universidade. Fortaleza: Universidade Federal do Ceará.

LIMA, Licínio C.; AZEVEDO, Mário Luiz Neves e CATANI, Afrânio Mendes Catani. (2008) O

Processo de Bolonha, a avaliação da educação superior e algumas considerações sobre a Universidade Nova. In: Avaliação, Campinas; Sorocaba, SP, v. 13, n. 1, p. 7-36, março.

MARCOVITCH, Jacques. (1998) A universidade (im)possível. São Paulo: Futura.

(2002) Os desafios da área de Humanidades no Brasil e no mundo. In: ESTUDOS AVANÇADOS. São Paulo 16 (46), 232-43.

NUSSBAUM, Martha. (2015) Sem fins lucrativos. Por que a democracia precisa das humanidades. São Paulo: Martins Fontes.

REINERT, José Nilson. A universidade como modelo de estrutura organizacional. Retirado de http://rapes.unsl.edu.ar/Congresos realizados/Congresos/IIIEncuentros/ Completos/RENERT.pdf.

RIBEIRO, Darcy. (1969) A universidade necessária. Rio de Janeiro: Paz e Terra.

ROJAS MIX, Miguel. (2006) El Imaginário: civilización y cultura del siglo XXI. Buenos Aires, Prometeu Libros.

. (2003) La Eñe: ucronia de una letra. A través del tiempo y los estilos. Colección

ExtremAmérica, CEXECI, Extremadura, España.

REYES, Abdiel Rodríguez. (2014) Las Humanidades entre las cuerdas del neoliberalismo. In: Revista Ensayos Pedagógicos, Panamá. Vol. IX, № 2, 169-175, julio-diciembre.

ROSSATO, Ricardo. (1998). Universidade: nove séculos de história. Passo Fundo: EDIUPF.

SARTORI, Giovanni. (1998). Homo videns. La sociedad teledirigida. Taurus: Pensamiento.

SERRÃO, Joaquim V. (1983) História das universidades. Porto: Lello e Irmão.

SGUISSARDI, Valdemar. A Universidade neoprofissional, heterônoma e competitiva. Retirado de www.lpp_uerj.net/olped/documentos/0470.pdf. Acesso em 23 de janeiro de 2008.

SILVA, Marcos Cipriano da. Reflexões sobre um modelo de universidade. Retirado de www.urutagua.uem.br/ru23_universidade.htm. Acesso em 23 de janeiro de 2008.

SPERANDIO, Décio. (1997) Administração universitária: a educação numa visão interdisciplinar.

Caderno de Administração, Maringá/Pr, v. 3, n. 1, p. 49-51, ago.

TRINDADE, Hélgio (org). (1999) Universidade em ruínas na República dos professores.

Petrópolis/Porto Alegre; Vozes/Cidade.

WANDERLEY, Luiz Eduardo W. (1998) O que é universidade? São Paulo: Editora Brasiliense. 9. ed. - Coleção Primeiros Passos. 